\title{
Perancangan Aplikasi Game Warung Sate Lilit Bali Berbasis Android Sebagai Media Pembelajaran Pengenalan Sate Lilit Secara Sederhana
}

\author{
I Made Ageng Suyasa, Putu Wira Buana, I Ketut Adi Purnawan \\ Program Studi Teknologi Informasi Universitas Udayana \\ Bukit Jimbaran, Bali, Indonesia, telp. (0361) 701806 \\ e-mail : suyasaageng@gmail.com, wbhuana@it.unud.ac.id, dosenadi@yahoo.com
}

\begin{abstract}
Abstrak
Makanan khas dari suatu daerah merupakan salah satu warisan budaya dari daerah yang harus dilestarikan dan dijaga agar tidak punah digerus oleh zaman. Sate lilit merupakan salah satu makanan khas dari Pulau Bali. Sate lilit merupakan olahan daging yang dicincang dan dicampur menggunakan berbagai macam bumbu khas bali yang dililit atau ditempel di sebuah katik bambu kemudian dipanggang di atas bara api. Game warung sate lilit bertujuan untuk mengenalkan kepada masyarakat umum dan generasi muda khususnya bagaimana cara pembuatan sate lilit secara sederhana, serta bertujuan sebagai media pembelajaran yang diharapkan mampu mendukung pelestarian sate lilit Bali. Game Warung Sate Lilit Bali diharapkan mampu meningkatkan minat generasi muda terhadap sate lilit sebagai makanan khas Pulau Bali. Game Warung Sate Lilit Bali dikembangkan dengan metode drag and drop, jadi user cukup memilih bahan yang telah disediakan kemudian muncul bar untuk menentukan takaran dari bahan yang diperlukan untuk memenuhi pesanan dari pembeli. Game Warung Sate Lilit Bali memberikan pembelajaran melalui informasi yang terdapat pada menu resep yang telah tersedia dan secara tidak langsung juga mendapatkan pembelajaran pada saat bermain, karena pada saat melakukan drag and drop bahan, pemain mengetahui apa saja bahan yang diperlukan dalam pembuatan sate lilit secara sederhana.
\end{abstract}

Kata Kunci: Sate Lilit, Game, Android, Drag and Drop, Budaya

Abstract

The typical food of an area is one of the cultural heritage of regions that should be preserved and maintained so the extinction never crushed by the time. Sate lilit is one of the typical foods in Bali. Sate lilit is processed by meats that are chopped and blended using a wide range of the balinese wrapped around or taped in a stalk of bamboo and then baked in hot coals. Warung Sate lilit game are aiming to introduce the general public and younger generation in particular how to make sate in a simple one turn, as well as aimed at the medium of learning are expected to support the preservation of sate lilit of Bali. Warung Sate Lilit Bali game is expected to increase the interest of the younger generation about satay lilit as the typical food of Bali. Warung Sate Lilit Bali game be played by the drag and drop method, so the user simply choose the materials provided by, then comes the bar to determine the dose of materials that are required to fulfill orders from buyers. Warung Sate Lilit Bali game are provide learning via the information contained on the menu ingredient which has been available and also get learning to play, because at the time to drag and drop the materials, the players knowing what course the necessary materials for making the sate lilit turn a simple.

Keywords: Sate Lilit, Game, Android, Drag and Drop, Culture 


\section{Pendahuluan}

Sate adalah makanan yang terbuat dari daging yang diolah menjadi potongan yang lebih kecil yang ditusuk sedemikian rupa dengan menggunakan tusukan lidi, tulang daun kelapa atau bambu yang kemudian dipanggang menggunakan bara arang kayu [1]. Sate biasanya disajikan dengan berbagai macam jenis bumbu olahan sesuai dengan resep daerah tertentu. Sate biasanya berbahan baku daging, seperti daging ayam, babi, dan ikan. Beberapa jenis sate terdapat di Indonesia, seperti sate tusuk dan sate lilit. Hampir di setiap daerah di Indonesia memiliki sate khas masing-masing tidak terkecuali Bali yang memiliki sate khas yaitu sate lilit. Sate lilit biasanya disajikan dengan sambal matah yang juga menjadi sambal khas dari Bali.

Penelitian sebelumnya mengenai makanan khas Bali yang dilakukan oleh Ida Bagus Danni Krisnawan berjudul Rancang Bangun Game Edukasi "Lawar Bali” pada Platform Android, tahun 2014 menjelaskan Game Lawar Bali, dimana pemain berperan sebagai pedagang pada sebuah warung makan yang menjual lawar. User sebagai pedagang harus membuat lawar sesuai pesanan pelanggan dalam waktu yang telah ditentukan. User dapat memperoleh poin atau nilai sesuai kecepatan dan ketepatan pesanan yang dibuat [2]. Penelitian sebelumnya yang mendukung pelestarian Budaya Bali adalah Rancang Bangun Game Tapel Bali pada Platform Android, AR banten otonan: A Learning Media Base on Augmented Reality Traditional Balinese Birthday Ceremony Equipment dan Application of Basic Balinese Dance Using Augmented Reality on Android. Penelitian yang berjudul Rancang Bangun Game Tapel Bali pada Platform Android dilakukan oleh I Dewa Made Yuda Aditya Putra, bertujuan untuk meningkatkan seni kerajinan tapel dari Daerah Bali kedalam bentuk permainan digital yang lebih modern [3]. AR banten otonan: A Learning Media Base on Augmented Reality Traditional Balinese Birthday Ceremony Equipment memberikan informasi mengenai proses pembuatan banten otonan dan sampian dalam kemasan 3D dengan metode augmented reality yang dilakukan oleh I Wayan Mei Sujana [4]. Penelitian dari Ni Putu Sinria Franza yang berjudul Application of Basic Balinese Dance Using Augmented Reality on Android memberikan pembelajaran dasar gerakan Tari Bali dengan lebih interaktif dan menarik dengan menggunakan vuforia yang mampu memutar suara dan menampilkan objek gambar 3D [5].

Sate lilit sebagai makanan khas daerah Bali melatarbelakangi pembuatan Game Warung Sate Lilit Bali. Game Warung Sate Lilit Bali, seperti halnya penelitian-penelitian sebelumnya bertujuan mendukung pelestarian Budaya Bali, namun dukungan pelestarian tersebut, ditujukan untuk sate lilit Bali. Game Warung Sate Lilit Bali dirancang mensimulasikan user sebagai pengelola warung sate dan berusaha melayani permintaan pelanggan. Game play dari Game Warung Sate Lilit Bali yaitu user merancang strategi dalam bermain agar mendapatkan hasil yang maksimal dari waktu yang sudah disediakan, game ini juga melatih kecekatan dan konsentrasi dari user. Selain sebagai game, Game Warung Sate Lilit Bali berbasis Android juga dirancang berfungsi sebagai media informasi dan pengenalan secara sederhana dari sate lilit. Penelitian dengan judul Rancang Bangun Game Warung Sate Lilit Bali berbasis Android dikembangkan dengan menggunakan metode drag and drop dan berbasis Android sehingga user dapat menggunakan smartphone sebagai basis penggunaannya.

\section{Metodologi}

Proses Rancang Bangun Game Aplikasi Warung Sate Lilit Bali Berbasis Android menggunakan alur penelitian berupa implementasi fungsi penggunaan Artificial Intelligence. Gambaran umum sistem merupakan gambaran sistem secara keseluruhan dan alur rancang bangun dalam pembuatan program aplikasi. Gambaran umum sistem dalam pembuatan Rancang Bangun Aplikasi Game Warung Sate Lilit Bali Berbasis Android memiliki beberapa tahap penting, yang berisikan gambaran umum dari alur permainan dan gambaran umum proses. Gambaran umum proses terdiri dari desain model program aplikasi yang dirancang dalam desain flow diagram. 


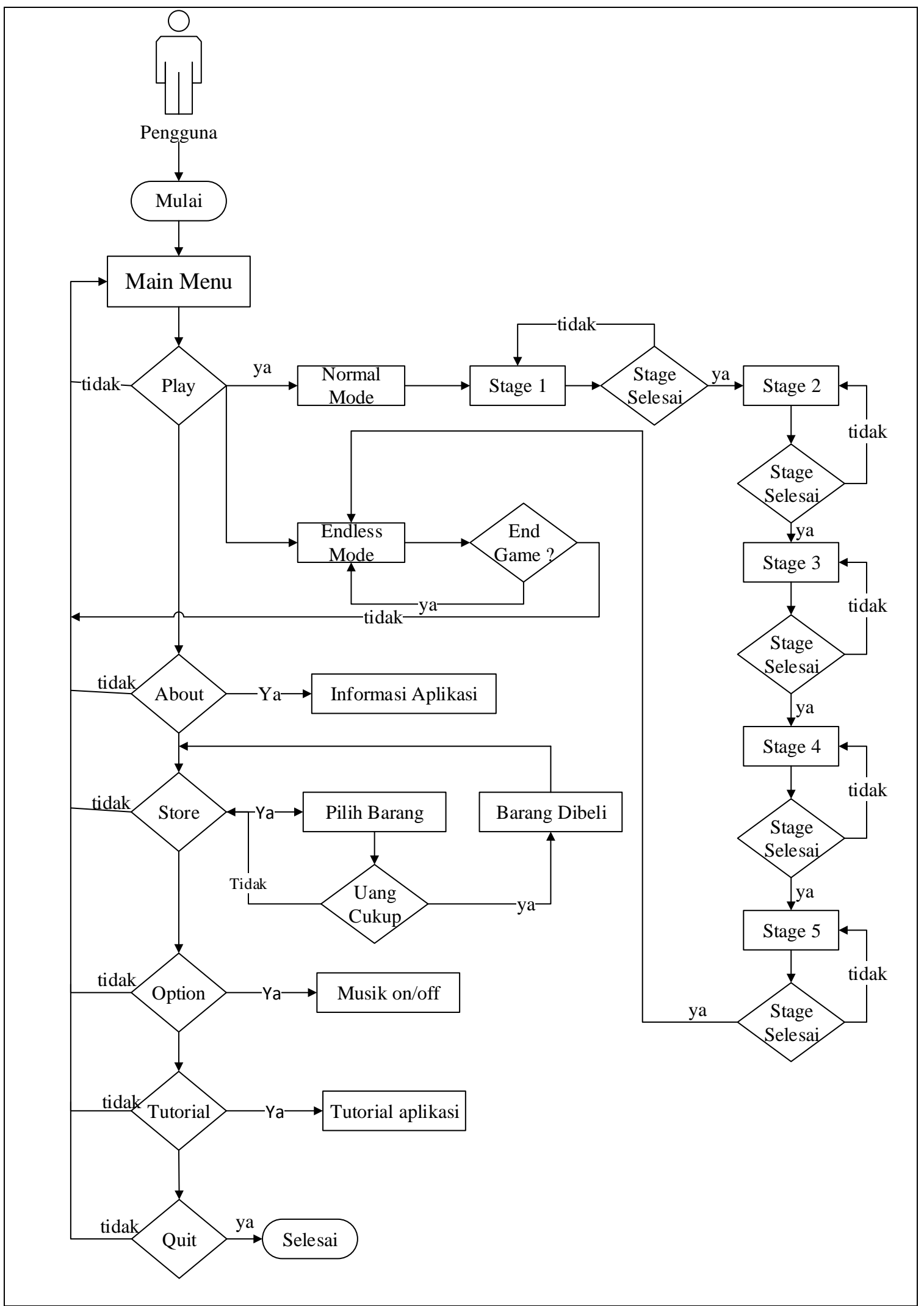

Gambar 1. Gambaran Umum Sistem

Gambar 1 merupakan Gambaran Umum Sistem dari Game Warung Sate Lilit Bali. Gambaran umum Game Warung Sate Lilit Bali memperlihatkan game terdiri dari beberapa fitur yaitu Play, About, Store, Option, Tutorial dan Quit. Game Warung Sate Lilit Bali memiliki 5 level 
biasa dan 1 level endless. Pemain memulai permainan dari level satu dan harus menyelesaikannya terlebih dahulu dengan cepat untuk mendapatkan poin terbaik agar level berikutnya terbuka. Level selanjutnya tetap terkunci jika pemain belum menyelesaikan level sebelumnya. Level endless tidak dapat terbuka jika pemain tidak menyelesaikan 5 level biasa sebelumnya.

\subsection{Diagram Use Case}

Diagram Use Case digunakan untuk memberi gambaran requirement fungsional dari Rancang Bangun Game Warung Sate Lilit Bali Berbasis Android, serta berguna untuk memperlihatkan bagaimana aplikasi digunakan olah user.

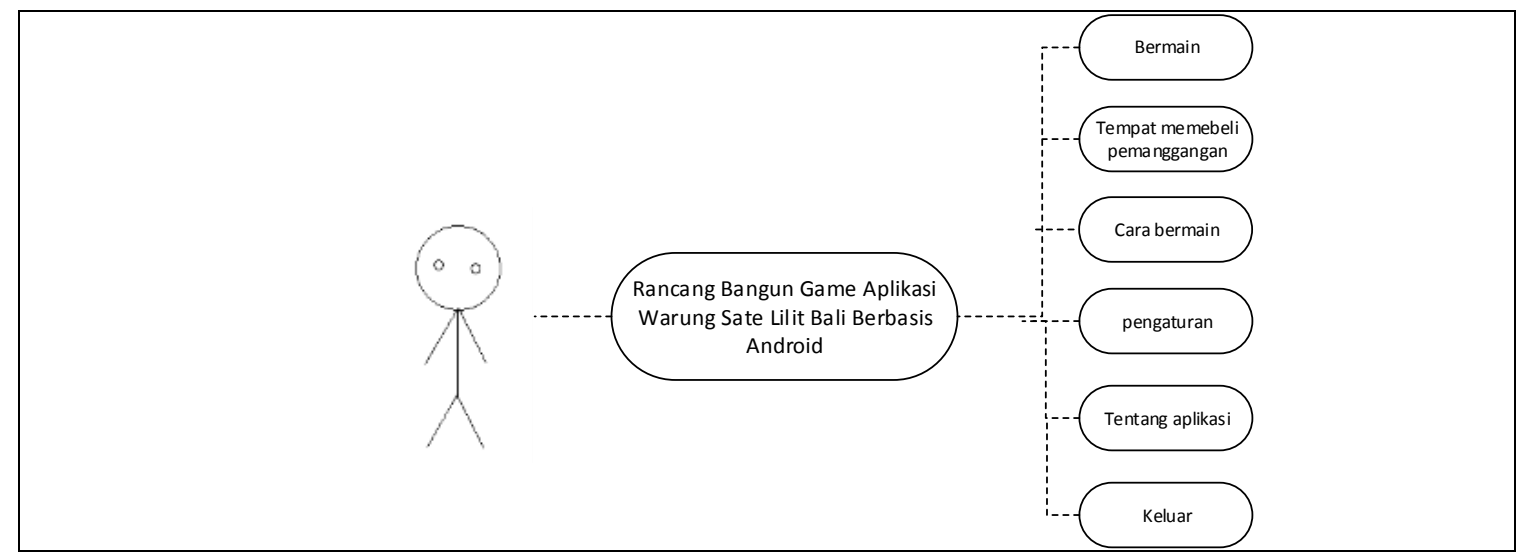

Gambar 2. Diagram Use Case

Gambar 2 terlihat beberapa fitur yang dapat dipilih oleh user. Bagian Menu Play merupakan bagian utama dari aplikasi Game Warung Sate Lilit Bali karena Menu Play merupakan menu untuk menuju gameplay utama dari Game Warung Sate Lilit Bali. Bagian Menu Store berisi tentang barang yang dapat di-upgrade, bagian Menu Option merupakan sebuah menu yang berfungsi untuk melakukan mute ataupun unmute sound dan music background. User disajikan informasi tentang aplikasi Game Warung Sate Lilit Bali pada Menu About. Bagian terakhir adalah Menu Quit berfungsi untuk keluar dari game.

\section{Kajian Pustaka}

Bab Kajian Pustaka berisikan teori yang digunakan sebagai penunjang dan yang menjadi dasar teori untuk pemecahan masalah dari penelitian yang dibuat.

\subsection{Sate Lilit}

Sate atau satai adalah makanan yang terbuat dari daging yang diolah dan dipotong kecilkecil kemudian ditusuk sedemikian rupa dengan tusukan lidi dari tulang daun kelapa atau bambu, kemudian melalui proses memanggang menggunakan bara arang kayu atau batok [1]. Sate dapat disajikan dengan berbagai macam bumbu olahan dan resep sesuai dengan daerahnya masing masing. Daging yang dapat dijadikan sate antara lain daging ayam, kambing, domba, sapi, babi, kelinci, kuda, dan lain-lain. Sate merupakan hidangan yang sangat populer di Indonesia, karena itu terdapat beragam olahan resep dari sate itu sendiri. Sate lilit merupakan makanan khas Provinsi Bali yang terbuat dari daging yang dihaluskan dan dicampur berbagai bumbu dan rempah-rempah. Daging yang digunakan untuk membuat sate lilit biasanya adalah ikan tuna, namun dalam perkembangannya, banyak juga yang membuat sate lilit menggunakan daging ayam dan babi. Sate lilit biasanya disajikan bersama sup daging, nasi hangat dan yang tidak boleh ketinggalan adalah sambal matah yang menjadi salah satu ciri khas dari pendamping sate lilit tersebut.

\subsection{Pengertian Game}

Game adalah salah satu jenis aktifitas yang dilakukan dan terlihat seperti nyata namun dalam konteks sebuah permainan. Pemain dalam sebuah permainan memiliki tujuan untuk mendapatkan satu kemenangan serta menghindari kekalahan yang dilakukan sesuai aturan 
permainan yang telah dibuat dan disetujui oleh setiap pemain [6]. Game edukasi adalah sebuah permainan hiburan yang dirancang sedemikian rupa sebagai media pembelajaran dan memiliki topik tertentu agar mendapatkan informasi serta pelajaran dari apa yang telah dimainkan [7].

\subsection{Bahasa Pemograman Lua}

Bahasa Pemograman Lua merupakan bahasa pemrograman yang ringkas dan dirancang sebagai bahasa pemrograman dinamis berbasis skrip dan dapat terus dikembangkan. Lua memiliki API dalam bahasa pemrograman $\mathrm{C}$ yang relatif sederhana dibandingkan bahasa skrip lainnya. Lua merupakan turunan dari data description atau configuration language yaitu SOL (Simple Object Language) dan DEL (Data Entry Language) [8]. SOL (Simple Object Language) dan DEL (Data Entry Language) telah dikembangkan secara independen oleh Tecgraf untuk menambahkan fleksibilitas 2 proyek yang berbeda (keduanya merupakan interactive graphical programs) untuk graphical engineering di Perusahaan Petrobas.

\subsection{Corona SDK (Software Development Kit)}

Corona SDK adalah SDK yang dibuat oleh Walter Luh yang merupakan founder dari Corona Labs Inc. Programmer software dapat menggunakan Corona SDK untuk membangun aplikasi mobile untuk aplikasi Android, Iphone, Ipad dan Windows. Corona menggunakan Bahasa Pemograman Lua yang sangat mudah dipelajari bahkan untuk pemula dalam hal pemograman. Corona Labs mempunyai 3 buah produk yakni Corona SDK, Corona Enterprise dan Corona Cloud [9].

Corona SDK berbeda dari yang sejenisnya, dimana didalam Corona SDK sendiri telah tertanam worksheet dan sistem debugging. Corona SDK membutuhkan editor teks dasar untuk menulis dan membuat kode serta membutuhkan editor grafis untuk pembuatan dan perancangan sebuah gambar [10]. User membutuhkan API Corona dan editor teks yang layak untuk memulai menggunakannya, karena Corona sendiri hanya berfungsi untuk menyusun dan running program.

\section{Hasil dan Pembahasan}

Bab Hasil dan Pembahasan berisikan hasil dari penelitian yang dilakukan berupa tampilan dari Game Warung Sate Lilit Bali.

\subsection{Tampilan Aplikasi Game Warung Sate Lilit Bali}

Sub bab ini membahas mengenai tampilan Game Warung Sate Lilit Bali pada scene yang ada pada game dan alur permainan atau gameplay yang dimiliki.

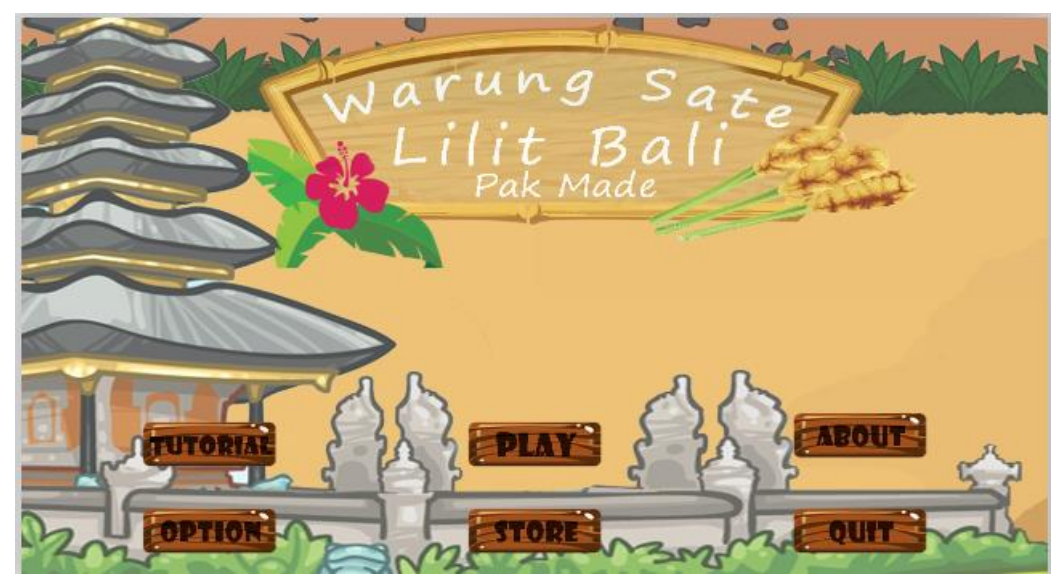

Gambar 3. Tampilan Main Menu

Gambar 3 merupakan Tampilan Main Menu pada Game Warung Sate Lilit Bali yang berisikan gambar dengan ciri budaya Bali dimana sate lilit merupakan bagian dari Budaya Bali. Main Menu juga berisikan button yang digunakan untuk berpindah scene. Button yang terdapat pada Main Menu antara lain Button Play, Button Store, Button Option, Button About dan Button Exit. 


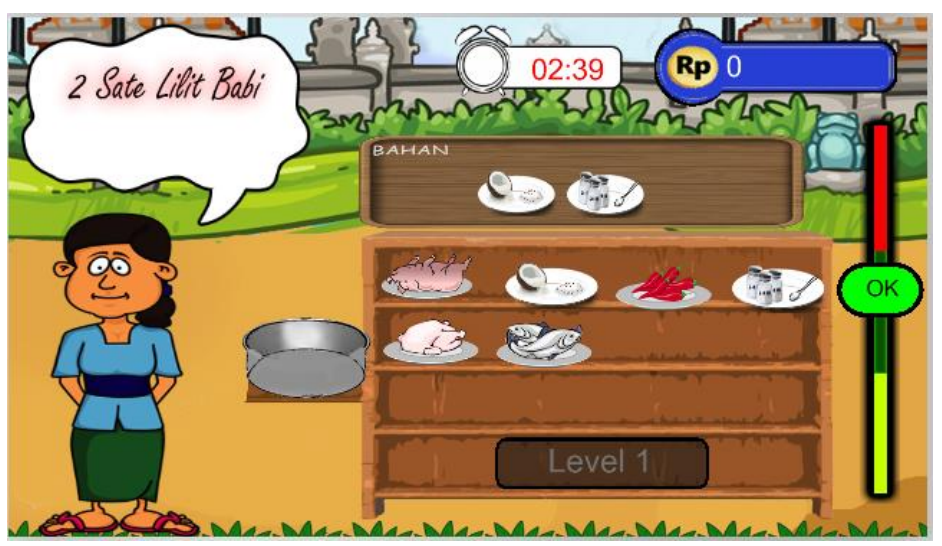

Gambar 4. Tampilan Scene Proses Bermain

Gambar 4 merupakan Tampilan Scene Proses Bermain, dimana pemain memilih bahan yang sesuai dengan panduan yang ada dan kemudian memilih takaran bahan menggunakan bar yang telah disediakan. Pemain cukup menekan tombol pada bar yang bergerak ketika berwarna hijau. Proses Pemanggangan dilakukan setelah user selesai memilih bahan dan menentukan takaran bahan menggunakan bar.

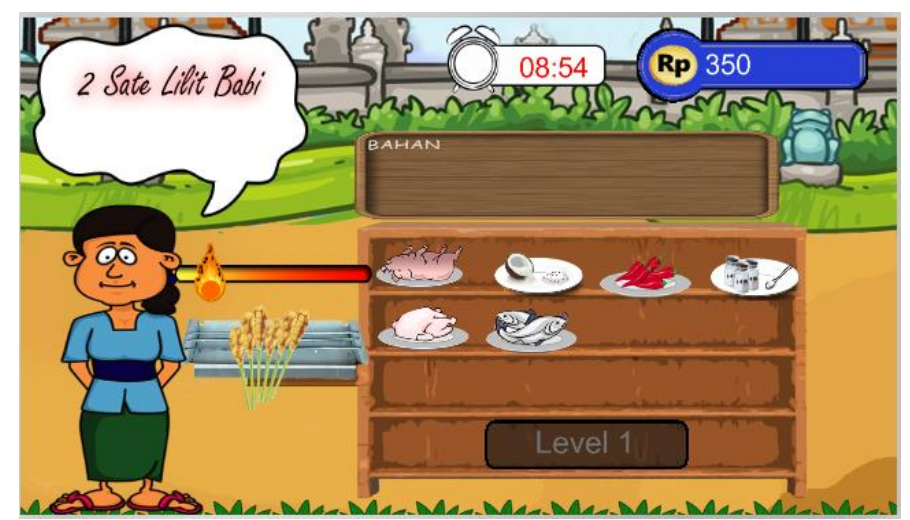

Gambar 5. Tampilan Scene Proses Memanggang

Gambar 5 merupakan Tampilan Scene Proses Memanggang, yang menampilkan fire bar dan Button Panggang. User dapat menekan Button Panggang untuk menentukan tingkat besar api yang diinginkan. Proses memanggang selesai ditandai dengan sate berubah warna dan muncul Button Lanjut yang berfungsi untuk meneruskan ke soal selanjutnya.

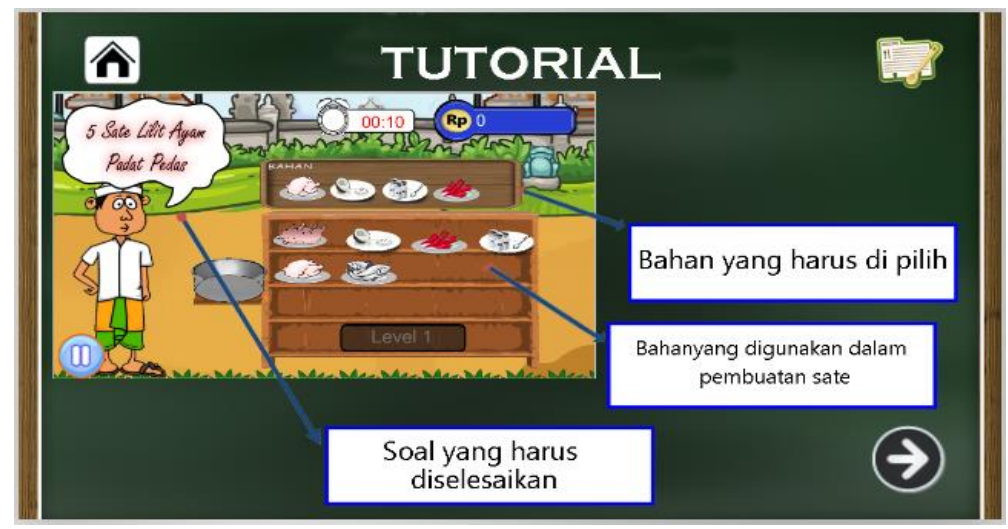

Gambar 6. Tampilan Scene Tutorial 
Gambar 6 merupakan Tampilan Scene Tutorial, tampilan scene yang berisikan bagaimana cara pemain memainkan permainan Warung Sate Lilit Bali dan pada menu tutorial juga terdapat tombol untuk memilih resep dari sate lilit yang ada.

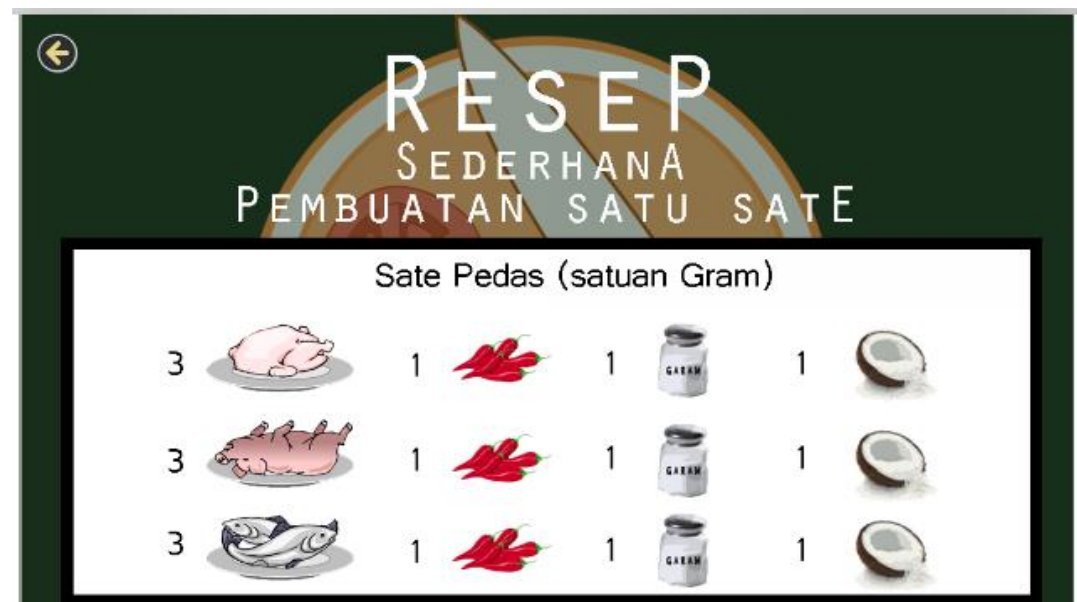

Gambar 7. Tampilan Resep pada Scene Komposisi Bahan

Gambar 7 merupakan Tampilan Resep pada Scene Komposisi Bahan, yang berisikan apa saja bahan dan komposisi untuk pembuatan dari satu buah sate lilit dalam Game Warung Sate Lilit Bali.

\subsection{Penilaian Kuesioner}

Bab Penilaian Kuesioner berisikan hasil dari penilaian berupa kuesioner yang telah dilakukan terhadap beberapa responden.

\subsubsection{Analisis Sistem Aplikasi}

Metode pengambilan data yang digunakan untuk melakukan pengujian pada Game Warung Sate Lilit Bali adalah menggunakan metode survey, dimana pengambilan data dilakukan dengan menggunakan kuesioner sebagai media survey. Survey melibatkan 61 responden yang terdiri dari anak-anak sekolah dasar.

\subsubsection{Aspek Pengalaman User}

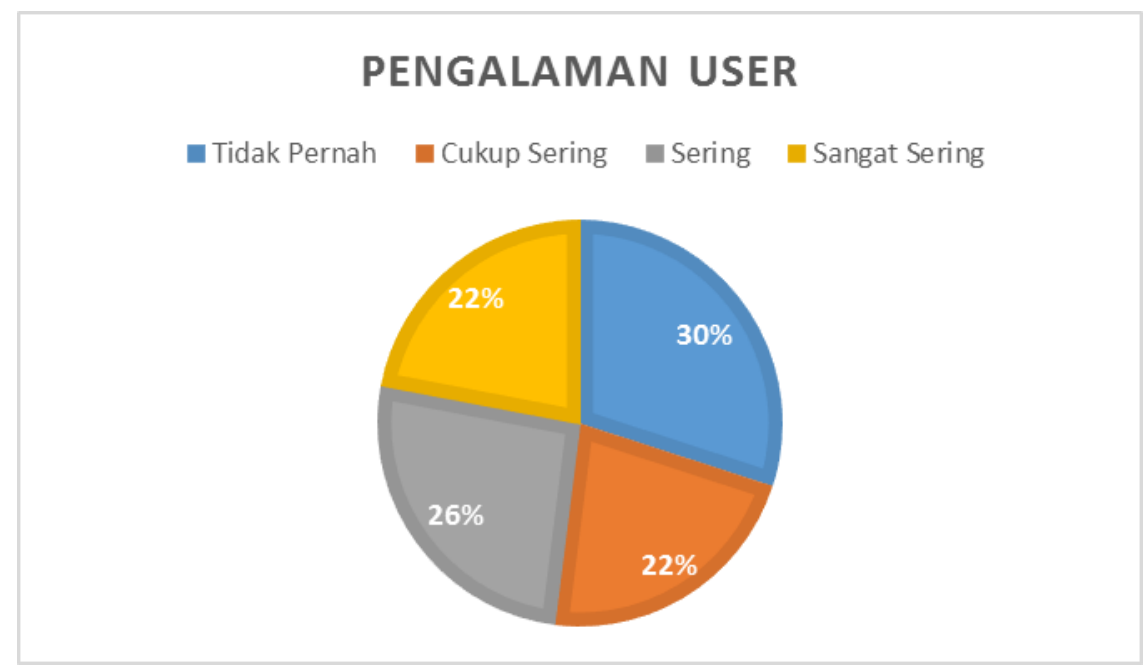

Gambar 8. Aspek Pengalaman user

Gambar 8 merupakan diagram aspek pengalaman user dari segi pengalaman bermain game dengan tema budaya dan bermain dengan gadget, responden memberikan persentase tertinggi terdapat pada pilihan tidak pernah, sehingga dapat disimpulkan bahwa aspek 
pengalaman user dari segi pengalaman bermain game dengan tema budaya masih banyak yang tidak pernah bermain walaupun sebagian besar user sudah sering bermain dengan smartphone.

\subsubsection{Aspek Grafis Game}

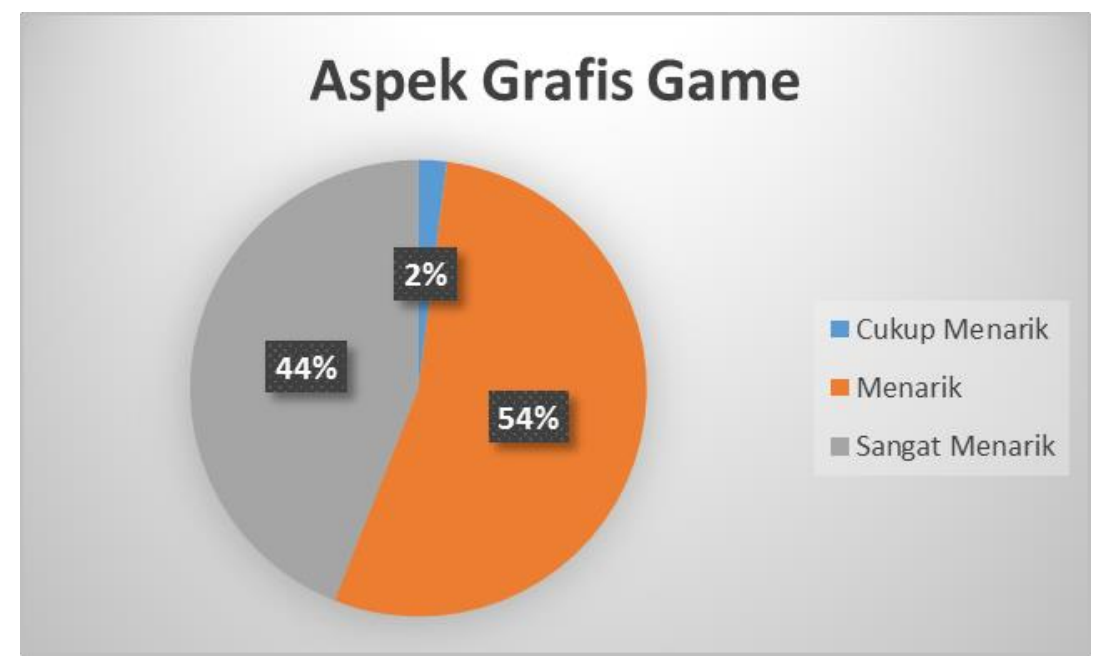

Gambar 9. Aspek Grafis

Gambar 9 merupakan diagram aspek grafis, responden memberikan persentase tertinggi terdapat pada pilihan menarik, sehingga dapat disimpulkan bahwa grafis dalam hal visual, audio, alur permainan serta tingkat kemudahan pada Game Warung Sate Lilit Bali menarik bagi user.

\subsubsection{Aspek Rekayasa Perangkat Lunak}

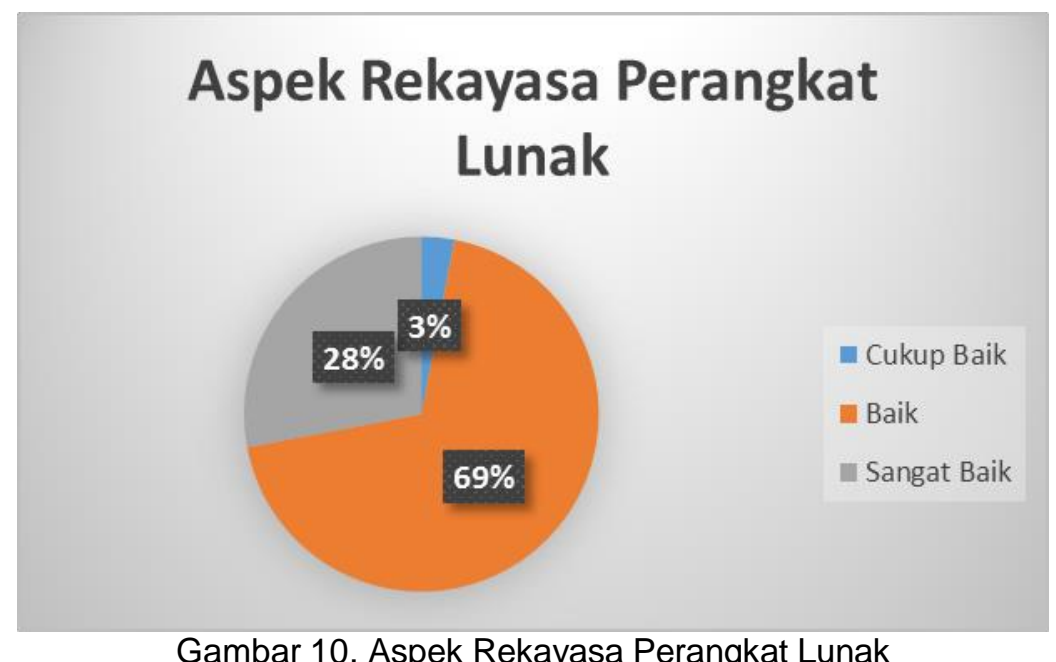

Gambar 10 merupakan diagram aspek rekayasa perangkat lunak, responden memberikan respon cukup baik dengan persentase tertinggi terdapat pada pilihan menarik, sehingga dapat disimpulkan bahwa rekayasa perangkat lunak dalam Game Warung Sate Lilit Bali menarik dan dapat berjalan dengan baik, hal ini dikarenakan pada Game Warung Sate Lilit Bali telah memenuhi user friendly, aplikasi tidak mudah error dan Game Warung Sate Lilit Bali dapat dijalankan pada berbagai OS yang berbasis Android. 


\subsubsection{Aspek Entertainment}

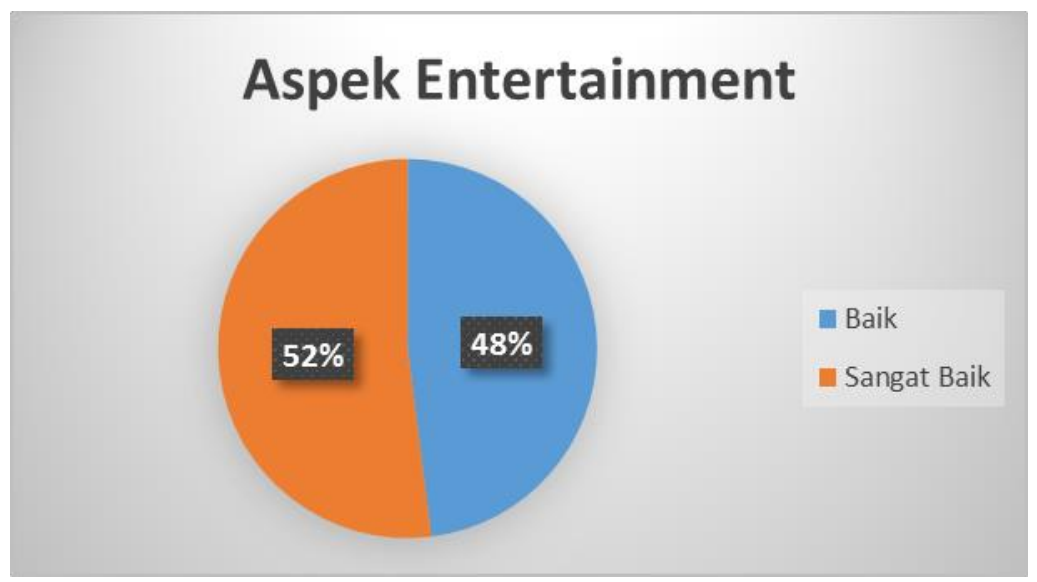

Gambar 11. Aspek Entertainment

Gambar 11 merupakan diagram aspek entertainment, responden memberikan respon cukup baik dengan persentase tertinggi terdapat pada pilihan sangat baik, sehingga dapat disimpulkan bahwa Game Warung Sate Lilit Bali dapat dijadikan media hiburan yang menyenangkan karena tingkat kesulitan dalam bermain Game Warung Sate Lilit Bali sangat cocok akan hal tersebut.

\subsubsection{Aspek Content}

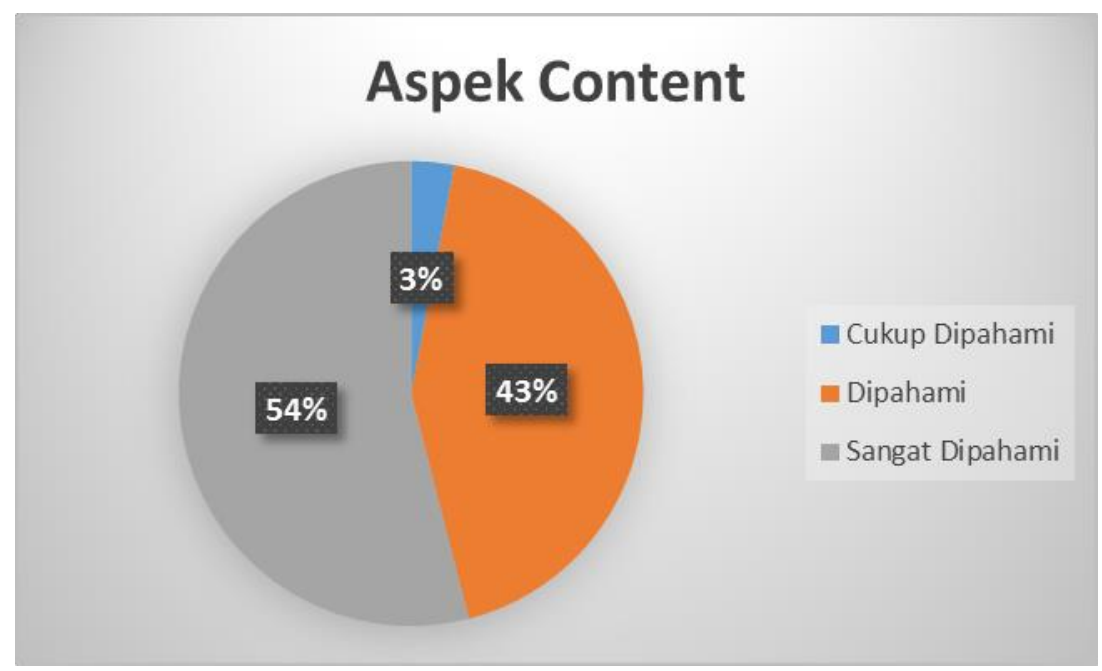

Gambar 12. Aspek Content

Gambar 12 merupakan diagram aspek content sebagian besar responden memberikan respon dengan persentase tertinggi terdapat pada pilihan sangat dipahami, sehingga dapat disimpulkan bahwa Game Warung Sate Lilit Bali berhasil memberikan pembelajaran dan pemahaman tentang resep dan cara pembuatan sate lilit Bali secara sederhana.

\section{Kesimpulan}

Kesimpulan yang dapat diambil dari Rancang Bangun Game Aplikasi Warung Sate Lilit Bali Berbasis Android adalah Game Warung Sate Lilit Bali memberikan pembelajaran melalui informasi yang terdapat pada menu resep yang tersedia dan secara tidak langsung juga mendapatkan pembelajaran pada saat bermain, karena pada saat melakukan drag and drop bahan, pemain mengetahui apa saja bahan yang diperlukan dalam pembuatan sate lilit secara sederhana. Kemampuan aplikasi dalam penyampaian pembelajaran ditunjukkan hasil survey yang dilakukan terhadap 61 orang anak sekolah dasar dan mendapatkan hasil baik pada segi 
content yang mencapai $98 \%$. Hasil dari survey kuesioner memperoleh hasil persentase bernilai baik pada aspek grafis sebanyak $98 \%$, pada aspek rekayasa perangkat lunak sebanyak $97 \%$ dan pada aspek entertainment mencapai 100\%, hasil tersebut menunjukkan Game Warung Sate Lilit Bali tergolong baik dari segi grafis dan menarik untuk dimainkan.

\section{Daftar Pustaka}

[1] Y. Boga, Dapur Indonesia 300 Resep Masakan Populer Nusantara, 1st ed. Jakarta: Gramedia Pustaka Utama, 2014.

[2] I. B. K. Danni, "Rancang Bangun Game Edukasi 'Lawar Bali' pada Platform Android," Merpati, vol. 2, 2014.

[3] I. D. Made, Y. Aditya, A. A. K. C. Wiranta, and P. W. Buana, "Rancang Bangun Game Tapel Bali Pada Platform Android," Lontar Komputer., vol. 6, no. 1, pp. 469-480, 2015.

[4] I. W. M. Sujana, A. A. K. Oka Sudana, and N. K. D. Rusjayanthi, "Arbantenotonan: A Learning Media Base On Augmented Reality Traditional Balinese," Journal of Theoretical and Applied Information Technology., vol. 95, no. 7, pp. 1362-1369, 2017.

[5] N. P. S. Franza, A. A. K. Oka Sudana, and K. S. Wibawa, "Application of basic Balinese dance using augmented reality on android," Journal of Theoretical and Applied Information Technology, vol. 90, no. 1, pp. 61-66, 2016.

[6] J. R. Situmorang, "Penggunaan Game Theory dalam IImu Sosial," Adm. Bisnis, vol. 11, no. 2, pp. 160-172, 2015.

[7] G. Agus, A. Prayoga, I. P. A. Bayupati, and A. A. K. A. C. Wiranata, "Game Edukasi Mengenal Huruf Katakana dan Hiragana Berbasis Android," Lontar Komputer., vol. 6, no. 3, pp. 621-633, 2015.

[8] J. Votano, M. Parham, and L. Hall, Beginning Lua Programming. Indianapolis: Wiley Publishing, Inc., 2004.

[9] T. Pdf and P. Bookshelf, "Extracted from : Create Mobile Games with Corona Build with Lua on iOS and Android," 2013.

[10] M. G. Arsawiguna, A. A. K. A. Agung, Wiranata, and K. S. Wibawa, "Rancang Bangun Aplikasi Game Tajen Berbasis Android menggunakan Artificial Intelligence," Lontar Komputer., vol. 6, no. 2, pp. 84-95, 2015. 